\title{
Affirmative action in procurement for open standards and FLOSS
}

\author{
Mathieu Paapst ${ }^{a}$ \\ (a) Teacher/researcher, Center for Law and IT, University of \\ Groningen, the Netherlands.
}

DOI: 10.5033/ifosslr.v2i2.41

\begin{abstract}
The Dutch action plan Netherlands Open in Connection intends to give a direction for public sector buyers to adopt a positive policy and strategy towards open standards and Free/Libre Open Source Software ("FLOSS"). This policy seems to indicate a preferred position on open source products, however it actually gives no guarantee that providers of FLOSS will get the opportunity to make a competitive offer. For this to be the case there ought to be a 'level playing field' for the FLOSS suppliers and closed source suppliers. However an empirical study carried out between January and June 2010 shows that despite the desired affirmative action for open source products, in almost half $(47.5 \%)$ of the tenders there is still a preference for closed source vendors or products. This preference inevitably results in not giving vendors of FLOSS a fair chance to win the bid.
\end{abstract}

\section{Keywords}

Public procurement; information technology; Free/Libre and Open Source Software

\section{Info}

This item is part of the Articles section of IFOSS L. Rev. For more information, please consult the relevant section policies statement. This article has been independently peer-reviewed.

In December 2007 the Dutch government agreed on the action plan Netherlands Open in Connection, hereafter called NOiV, the Dutch acronym. The objectives of this action plan are the following:

1. increase interoperability by accelerating the use of open standards; 
2. reduction of supplier-dependence through a faster introduction of open source software and open standards;

3. promotion of a level playing field in the software market, promotion of innovation and of the economy by forceful stimulation of the use of open source software, and by giving preference to open source software during the process of IT acquisition.

To reach these goals the action plan described a number of policies for open standards and open source software. A vast number of these policies directly affected the process of IT procurement within government organisations. A central question for research has been selected: How and under what circumstances does a policy like the action plan NOiV influence behaviour regarding the practice of public tenders?

A subsidiary question is: "Does European procurement law give a fair chance to vendors of FLOSS software or do we need a affirmative action in order to guarantee fair competition?"

\section{Dutch principles and policies}

The action plan NOiV describes three principles for the acquisition of FLOSS by organisations in the (semi) public sector.

\section{Principle 1: Open source is not mandatory, but its use should be strongly encouraged.}

This principle primarily intends to give a direction for politicians and civil servants to adopt a positive policy and strategy towards open source software. It means that organisations in the (semi) public sector, although not required to choose open source software in all cases, are expected to promote the use of open source software within their organisation. By January 2010 they had to develop an implementation strategy for the procurement, purchase and use of open source software. The political administrative preference for open source software then needed to be translated into that strategy.

\section{Principle 2: Open source software should be preferred if it is equally suitable.}

This principle intends to give a direction for government buyers to adopt a positive policy and strategy towards open source software. A possible way to do this is to prescribe weighted award criteria that create a preference for vendor independent solutions. Award criteria in a tender shall be clear and unambiguous and the assessment method must be verifiable, transparent and objective. ${ }^{1}$ It is therefore important for public sector buyers to clarify the conditions required for the IT solution in advance in order that suppliers will be put in a position to submit their strongest bids ans obtain the highest number of points they can. As long as they relate to the object of the tender the tendering organisation is free to apply various criteria to determine the most economically advantageous offer, including so-called vendor independent award criteria.

The following are examples of vendor independent award criteria:

1 Directive 2004/18/EC 
- The software is database independent and works with databases of several suppliers, including open source databases.

- The user interfaces are browser independent.

- The software can run on more than one operating system (eg. Windows, Linux or Apple).

- Support for the software can be delivered by several (independent) suppliers.

- There are one or more independent user groups or free accessible communities involved in the further development of the software.

- The software uses open specifications and standards.

- The legal terms of use refer to aspects such as availability of the source code and the conditions for modification and distribution of the software.

Determining the weight of such award criteria in terms of percentage could also be included in the implementation strategy document. If an organisation actually prefers supplier independent software they can use a high weighting for these criteria. Although the criteria do not exclude closed source proprietary solutions, they can value a bid using FLOSS and open standards more than an equivalent and equally suitable bid using closed source proprietary software.

\section{Principle 3: Providers of open source software should have the same opportunities as} providers of closed source software.

Although the two principles discussed above seem to indicate a preferred position for Free and Open source software at first glance, they actually give no guarantee whatsoever that providers of FLOSS will get the opportunity to make a competitive offer. For this to be the case there ought to be a 'level playing field' for the Free and open source software providers and the closed source software suppliers. The action plan mentions this in the following way:

"The Cabinet wants procurement and purchasing processes of software to give the same opportunities to providers of open source software (...)." ${ }^{2}$

This is a surprising admission by the Dutch government: that the current European procurement laws and procedures have not yet accomplished the creation of this level playing field in the software market and are therefore, one could argue, not realizing their initial goal which is stimulating competition in order to complete the European single market.

Dutch vendors of proprietary closed source software however argued that the preference of the Dutch government for Free and Open source software is in fact a violation of European procurement laws. ${ }^{3}$

2 Actionplan Netherlands Open in Connection, p.17

http://www.whitehouse.gov/files/documents/ostp/opengov inbox/nl-in-open-connection.pdf

3 See e.g.: http://www.channelweb.nl/nieuws.jsp?id=3196657 (Dutch) 


\section{Research}

To see if European procurement law does give a fair chance to vendors of FLOSS empirical quantitative research was carried out which asked for the data of 94 Dutch calls for tender, published between January and June 2010, that followed the open procedure and that consisted of the delivery of software of some kind. ${ }^{4}$ Out of the total sample of 94 calls, data relating to 80 tenders was received, a response rate of $85,1 \%$.

All these tender documents were examined on 25 different aspects, such as the needs or wants for open standards, vendor independent award criteria, the possibility to use ODF (a document format based on an open standard) for the bid and the possible preference for open or closed source products.

\section{Results}

The following results emerged:

In 36 cases $(45 \%)$ the tender documents mentioned a need or want for open standards in general. In the remaining 44 cases open standards were not requested. This is not a very positive result considering the fact that it has been Dutch policy to ask for open standards since 2002 when the Dutch Parliament adopted the motion "Vendrik." ${ }^{5}$ Under that motion the government was asked to ensure that by 2006 all public sector software used open standards. To reach this ambitious goal it would seem necessary to ask for open standards in all public sector tenders.

\begin{tabular}{|l|l|l|}
\hline \multicolumn{1}{|c|}{$\begin{array}{c}\text { Request for open } \\
\text { standards }\end{array}$} & \multicolumn{1}{|c|}{ Frequency } & Percent \\
\hline Yes & 36 & 45 \\
\hline No & 44 & 55 \\
\hline
\end{tabular}

Table 1: Frequency of needs and wants for open standards

The possibility of a vendor using the odt (ODF) format for his bid was considered. According to the action plan all the ministries and subsidiary government bodies should be able to receive documents in the ODF open standard by January 2009 at the latest. ${ }^{6}$

In almost half of the cases (45\%) the use of ODF was possible. In the other $46.2 \%$ it was not

4 The tenders that asked for Voice over IP technologies or printer hardware with printer drivers were not included in the sample of 95 tenders due to technical expertise limitations.

5 Lower Chamber, 2002/2003, 28600 XIII, nr. 30 (Dutch) The motion, named after its initiator Kees Vendrik, who is a former member of Dutch parliament, also asked for ambitious steps to ensure the preference and stimulation of FLOSS.

6 Actionplan Netherlands Open in Connection, p.9 http://www.whitehouse.gov/files/documents/ostp/opengov inbox/nlin-open-connection.pdf 
possible, however this was mainly caused because the tendering organisation demanded the use of the PDF format. Only in one case both PDF and ODF were not possible because a vendor was obliged to use a Microsoft Word and excel format suitable for Windows XP.

In the 7 remaining cases $(8.8 \%)$ a digital bid was not requested by the tendering organisation.

\begin{tabular}{|l|l|l|}
\hline \multicolumn{1}{|c|}{$\begin{array}{c}\text { Possibility of using } \\
\text { ODF }\end{array}$} & \multicolumn{1}{|c|}{ Frequency } & Percent \\
\hline Yes & 36 & 45 \\
\hline No & 37 & 46.2 \\
\hline n/a & 7 & 8.8 \\
\hline
\end{tabular}

Table 2: Frequency of possibilities to deliver the bid in ODF

Looking at the possible presence of a preference for FLOSS, in 22 cases (27.6\%) a preference for FLOSS, or more particularly "Open source licensing", was mentioned. This was mostly done by mentioning the action plan NOiV as a principal guideline for the procurement of software or by actually mentioning that the customer preferred open source software. One should keep in mind that this is not the same as a preference for a named open source product or vendor. At first glance $27.6 \%$ seems to be a positive result, however in only 15 cases $(18.8 \%)$ the preference actually resulted in a reward of extra points under the weightings applied to the award criteria. This means that in 7 cases (8.8\%) a preference has been mentioned, but a vendor would not get extra points for offering a FLOSS product. In 1 case there was a preference for FLOSS combined with a clear preference for a named enterprise edition "open source" product. For the purposes of this survey, this was counted as a preference for FLOSS with reward of extra points . However, it is highly debatable whether an "enterprise edition" can fulfil the same goals as a community edition whether it helps to reach the NOiV objective of reducing the dependence on suppliers. There is a strong argument that buying an enterprise edition which is not being delivered under an OSI approved license (or something broadly similar) is basically the same as a closed source proprietary product, having the same disadvantages. 


\begin{tabular}{|l|l|l|}
\hline \multicolumn{1}{|c|}{$\begin{array}{c}\text { Preference for } \\
\text { FLOSS }\end{array}$} & \multicolumn{1}{|c|}{ Frequency } & Percent \\
\hline $\begin{array}{l}\text { FLOSS preferred and } \\
\text { rewarded }\end{array}$ & 15 & 18.8 \\
\hline $\begin{array}{l}\text { FLOSS preferred but } \\
\text { not rewarded }\end{array}$ & 7 & 8.8 \\
\hline FLOSS not preferred & 58 & 72.4 \\
\hline
\end{tabular}

Table 3: Preference for FLOSS

The tender documents were examined for a preference for closed source software, and in particular a preference for a named closed source product or vendor. The mere use of a trademark or product name in public procurement (which is actually a widespread practice) ${ }^{7}$ was not, by itself, considered sufficient to demonstrate such a preference. In lots of cases trademarks and product names are used to describe both the current architecture and the software the new solution has to integrate with. ${ }^{8}$ For the purpose of this study, such a use of trademarks and product names was not taken to have established a clear preference for a product or vendor, although one could argue that it becomes a discriminating preference the moment compatibility is required with previously purchased proprietary software, especially if the technical specifications needed for that compatibility are not publicly available and freely usable. ${ }^{9}$

For the purposes of this study, actual discriminatory use of trademarks, patents, types, and legal and technical conditions in relation to the vendor or product which was the subject of the procurement needed to be present in order to establish a preference for closed source vendors or products. In 29 cases $(36.2 \%)$ a clear preference for a named closed source product or a closed source vendor was found. Accordingly in these 29 cases other vendors than the preferred one did not have a fair chance to win a bid.

7 See e.g. OpenForum Europe, 2008. "OFE Monitoring Report: Discrimination in Public Procurement Procedures for Computer Software in the EU Member States", where 34 out of 136 tender notices mention trademarks in procurement documents. http://www.openforumeurope.org/press-room/press-releases/procurement-study-release.pdf

8 According to Rishab Gosh et al, "Guidelines on Public Procurement of Open Source Software", this might not be a legitimate functional requirement according to article 23 (8) of the Directive 2004/18/EC since software can usually be described in terms of standards and functionality.

9 In decision T-345/03 of 12/03/2008 the Court of first instance of the European Community considers that the Commission infringed the principle of equal treatment as between tenderers by failing to make available to all the prospective tenderers from the beginning of the tendering procedure the documentation relating to the technical architecture and source code and that that infringement could thus have affected the award of the contested contract. http://curia.europa.eu/ 


\begin{tabular}{|l|l|l|}
\hline $\begin{array}{c}\text { Preference for } \\
\text { closed source } \\
\text { vendor or product }\end{array}$ & Frequency & Percent \\
\hline Yes & 29 & 36.3 \\
\hline No & 51 & 63.7 \\
\hline
\end{tabular}

Table 4: Preference closed source vendor or product

In practice there are many examples of discriminatory criteria used to give a preferred position to named closed source proprietary software or vendors, including:

1. Asking for a named product or licence of a named product (eg. tender for Windows licenses)

2. Asking for a reseller of either licences of the closed source installed base or new named closed source software.

3. The vendor must be a certified and recognised partner of a named closed source product.

4. The vendor must have an agreement with Microsoft for technical support on the product.

5. The product must be certified by a named closed source vendor.

6. The vendor must deliver a new product and have permission to expand the closed source installed base.

7. The vendor must employ Microsoft certified employees.

8. Asking for an operating system that can be downgraded to Windows XP.

9. Asking for an operating system that can be used together with the Microsoft Campus Agreement.

10. Tendering for hardware (e.g. laptops) while also asking for named software (in most cases Microsoft) to be installed on that hardware.

In two of these 29 cases the tendering organisations actually mentioned that they had a preference for a named closed source product and vendor.

Finally some of the other criteria that could prevent vendors, and in particular FLOSS vendors, from making a bid and having a fair chance of winning were considered. In 9 other cases restrictions were found that made it very difficult or impossible for vendors to offer a FLOSS product.

Some examples of these criteria are the following:

1. If your bid is open source you should give extra guarantees concerning the stability of the open source community. 
2. The vendor has to be the copyright owner.

3. Extra points are to be awarded if interoperability with a named closed source product is already integrated within the offered product.

4. Not allowing licences to be offered for a "zero-price".

5. Demanding that offered applications must be certified by Microsoft, are Oracle 10 compliant and use the official Microsoft style guide as much as possible.

\begin{tabular}{|l|l|l|}
\hline \multicolumn{1}{|c|}{$\begin{array}{c}\text { Restrictions } \\
\text { preventing fair } \\
\text { competition }\end{array}$} & Frequency & \multicolumn{1}{c|}{ Percent } \\
\hline Yes & 38 & 47.5 \\
\hline No & 42 & 52.5 \\
\hline
\end{tabular}

Table 5: Frequencies of restrictions for FLOSS vendors

This shows that despite the desired affirmative action for Free/Libre and Open Source Software in almost half $(47.5 \%)$ of the sampled tenders there was still a preference for closed source vendors or products. This preference inevitably results in vendors of FLOSS products not receiving a fair chance to win the bid.

The last question to be considered was whether or not it would make any difference to the prevalence of these restrictions if a tender was organised completely by the tendering organisation itself or if the procurement process was "outsourced" to an external advisor or company. A reasonable hypothesis would be that the external advisors, who are presumably all experts in the field of procurement, would do better in following the EU directives. After comparing the numbers this hypothesis proves to be wrong. In $36.7 \%$ of the sixty internally guided procedures there were restrictions on FLOSS vendors or products. In the twenty externally guided procedures however, these restrictions were found in $80 \%$ of the cases.

\begin{tabular}{|l|l|l|}
\hline \multicolumn{1}{|c|}{$\begin{array}{c}\text { Restrictions } \\
\text { preventing fair } \\
\text { competition }\end{array}$} & \multicolumn{1}{|c|}{ Internal (N=60) } & \multicolumn{1}{|c|}{ External (N=20) } \\
\hline Yes & $22(36.7 \%)$ & $16(80 \%)$ \\
\hline No & $38(63.3 \%)$ & $4(20 \%)$ \\
\hline
\end{tabular}

Table 6: Frequencies of restrictions in externally and internally guided procedures 


\section{Conclusion}

This research shows that despite the desired affirmative action for Free/Libre and Open Source Software, in almost half $(47.5 \%)$ of the tenders there is a preference for closed source vendors or products. Because of this preference vendors of FLOSS products are not given a fair chance to win the bid. There is no level playing field on the software market and government buyers arguably do not act according to the EU treaty principles of equal treatment, non-discrimination and transparency. Further research will try to determine why public sector buyers disregard the EU directives and regulations and how FLOSS vendors experience this behaviour. 


\begin{abstract}
About the author
Mathieu Paapst holds a masters degree in Law and IT and works as a lecturer and PhDresearcher at the Center for Law and IT, University of Groningen. He is interested in legal and social aspects of IT procurement, copyright licensing and e-Health, and has been publishing about open standards and free software since 2005.
\end{abstract}

\title{
Licence and Attribution
}

This paper was published in the International Free and Open Source Software Law Review, Volume 2, Issue 2 (December 2010). It originally appeared online at http://www.ifosslr.org.

This article should be cited as follows:

Paapst, Mathieu (2010) 'Affirmative action in procurement for open standards and FLOSS', IFOSS L. Rev., 2(2), pp $181-190$

DOI: $\underline{10.5033 / \text { ifosslr.v2i2.41 }}$

Copyright (C) 2010 Mathieu Paapst.

This article is licensed under a Creative Commons UK (England and Wales) 2.0 licence, no derivative works, attribution, CC-BY-ND.

As a special exception, the author expressly permits faithful translations of the entire document into any language, provided that the resulting translation (which may include an attribution to the translator) is shared alike. This paragraph is part of the paper, and must be included when copying or translating the paper.

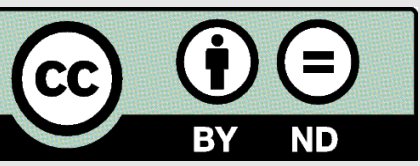

